\title{
Effectiveness of $\mathrm{CO}_{2}$-insufflated endoscopic submucosal dissection with the duodenal balloon occlusion method for early esophageal or gastric cancer: a randomized case control prospective study
}

Hirohito Mori ${ }^{1 *}$, Hideki Kobara ${ }^{1}$, Shintaro Fujihara ${ }^{1}$, Noriko Nishiyama ${ }^{1}$, Kunihiko Izuishi ${ }^{2}$, Masaomi Ohkubo ${ }^{3}$, Kazi Rafiq ${ }^{4}$, Yasuyuki Suzuki ${ }^{2}$ and Tsutomu Masaki ${ }^{1}$

\begin{abstract}
Background: Endoscopic submucosal dissection (ESD) has typically been performed using air insufflation. Recently, however, insufflation of $\mathrm{CO}_{2}$ has been increasingly used to avoid complications. This prospective study was designed to compare the $\mathrm{CO}_{2}$ concentration, intestinal volume, and acid-base balance using the duodenal balloon procedure.

Methods: From June 2010 to February 2011, we enrolled 44 patients with esophageal or gastric cancer and randomly allocated them into two groups. We compared 22 patients undergoing $\mathrm{CO}_{2}$-insufflated ESD with a balloon placed into the duodenal bulb (duodenal balloon group) and 22 patients undergoing regular $\mathrm{CO}_{2}$-insufflated ESD (regular group). Three-dimensional computed tomography was performed before and after the procedure to measure intestinal volume. $\mathrm{CO}_{2}$ concentrations were measured every 10 minutes. The visual analogue system (VAS) scores for postoperative symptoms were recorded, and $\mathrm{pH}$ was measured immediately after the procedure. This was a prospective case control study randomized by the sealed envelope method.
\end{abstract}

Results: Intestinal $\mathrm{CO}_{2}$ gas volume before and after ESD was lower in the duodenal balloon group than in the regular group $(P=0.00027)$. The end-tidal $\mathrm{CO}_{2}$ level was significantly lower in the duodenal balloon group than in the regular group $(P=0.0001)$. No significant differences in blood $\Delta \mathrm{pH}$ were found between the two groups. The VAS score for the occurrence of nausea due to abdominal distension after ESD indicated a significant difference $(P=0.031)$.

Conclusions: ESD using the duodenal balloon occlusion method is effective for reduction of post-ESD intestinal $\mathrm{CO}_{2}$ gas volume, resulting in a lower total amount of $\mathrm{CO}_{2}$ insufflation during ESD and reducing harmful influences on the human body to some extent.

\section{Background}

Endoscopic submucosal dissection (ESD) for gastrointestinal malignancy has been increasingly performed in Japan, and its technical basis is almost completely established [1-4]. The procedure is also covered by the health insurance system in Japan. However, ESD is technically complicated $[5,6]$, requires a high level of endoscopic

\footnotetext{
* Correspondence: hiro4884@med.kagawa-u.ac.jp

'Department of Gastroenterology and Neurology, 1750-1 Ikenobe, Miki, Kita, Kagawa 761-0793, Japan

Full list of author information is available at the end of the article
}

skill, and has been associated with serious complications $[7,8]$. Although insufflation of air has traditionally been used in ESD, there are many risks, such as air embolism. As an alternative to air, insufflation of $\mathrm{CO}_{2}$ has been used in regular colonoscopy and colorectal ESD which has been proven effective [9-17]. Insufflation of $\mathrm{CO}_{2}$ is also available to help maintain a stable respiratory and hemodynamic state during ESD by preventing pneumoperitoneum when perforation occurs [18-21] and reducing post-ESD symptoms, such as nausea due to abdominal distension. In addition, given recent issues 
related to air insufflation, such as air embolism, insufflation of $\mathrm{CO}_{2}$ is expected to become increasingly more common.

The present study was a prospective comparison of changes in $\mathrm{CO}_{2}$ concentration during the procedure and changes in intestinal volume and acid-base balance using the duodenal balloon occlusion method.

\section{Methods \\ Patients}

We enrolled 44 patients who were diagnosed with early gastric or esophageal cancer and demonstrated expanding indications for ESD by the gastric cancer treatment guidelines of the Japanese Gastric Cancer Association (JGCA). The expanding indications of ESD are as follows: mucosal differentiated adenocarcinoma of any size without ulceration, SM1-invaded differentiated adenocarcinoma within $3 \mathrm{~cm}$ in diameter, and mucosal undifferentiated adenocarcinoma within $2 \mathrm{~cm}$ in diameter without ulceration. All patients underwent ESD using $\mathrm{CO}_{2}$ insufflation.

We randomly allocated 44 patients (34 males and 10 females) who underwent ESD for early esophageal or gastric cancer into two groups by the sealed enveloped method from June 2010 to February 2011 (Table 1). The exclusion criteria were a past history of a duodenal ulcer or the presence of an ulcer scar.

We informed all patients of this study's aim and method. Full details of patients' informed consents were followings: using the balloon for esophageal variceal injection sclerotherapy as duodenal occlusion balloon. An overtube was used to allow backflow of $\mathrm{CO}_{2}$ gas from the stomach to the oral cavity for evacuation from the mouth, preventing the gas from flowing into the trachea and lungs. Under putting the balloon, we would perform ESD. We informed these procedures and side effects,

\begin{tabular}{|c|c|c|c|}
\hline & $\frac{\text { Duodenal balloon }}{\frac{\text { group }}{n=21}}$ & $\frac{\text { Regular group }}{n=22}$ & $P$ value \\
\hline $\begin{array}{l}\text { Age(years) } \\
(\text { mean } \pm S D)\end{array}$ & $\begin{array}{c}50 \sim 79 \\
(69.0 \pm 9.8)\end{array}$ & $\begin{array}{c}40 \sim 85 \\
(71.6 \pm 12.7)\end{array}$ & $N S^{* *}$ \\
\hline $\begin{array}{l}\text { Gender } \\
(\mathrm{M} / \mathrm{F})\end{array}$ & $17 / 4$ & $16 / 6$ & $N S^{*}$ \\
\hline $\begin{array}{l}\text { Location of lesion } \\
\text { (Eso/U/M/L) }\end{array}$ & $4 / 8 / 4 / 5$ & $2 / 8 / 5 / 7$ & $N S^{* *}$ \\
\hline $\begin{array}{l}\text { Size of resected } \\
\text { specimen (mm) }\end{array}$ & $\begin{array}{c}17 \sim 80 \\
(36.1 \pm 19.3)\end{array}$ & $\begin{array}{c}17 \sim 70 \\
(38.8 \pm 17.9)\end{array}$ & $N S^{* *}$ \\
\hline $\begin{array}{l}\text { Procedure time } \\
\text { (min) }\end{array}$ & $\begin{array}{c}105 \sim 180 \\
(145.6 \pm 26.6)\end{array}$ & $\begin{array}{c}30 \sim 270 \\
(127.0 \pm 67.3)\end{array}$ & $N S^{* * *}$ \\
\hline
\end{tabular}

${ }^{*}$ Fisher's exact t-test, ${ }^{* *}$ Unpaired t-test, ${ }^{* * *}$ Mann-Whitney U-test. and obtained consents from all patients in written forms. The study protocol was reviewed and approved by the Kagawa university ethical committee according to the Declaration of Helsinki. All subjects gave written, informed consent before any study related procedures were performed.

\section{Study design}

This was a single-center, randomized, case control study. The objectives were to examine the intestinal $\mathrm{CO}_{2}$ gas volume measured by three-dimensional computed tomography (3DCT) before and after ESD using the duodenal balloon occlusion method and determine the effect on certain parameters between in the duodenal balloon group and regular group.

We performed ESD on 44 patients. We performed $\mathrm{CO}_{2}$-insufflated ESD with a duodenal balloon in 22 patients (duodenal balloon group) and regular $\mathrm{CO}_{2}$ insufflated ESD without the balloon in 22 patients (regular group). The duodenal balloon occlusion method is described in following section. 3DCT was performed the day before ESD and just after the ESD to measure intestinal gas volume. $\mathrm{CO}_{2}$ concentrations were measured every 10 minutes by a capnometer (end-tidal $\mathrm{CO}_{2}$; $\mathrm{PETCO}_{2}$ ) every $10 \mathrm{~min}$ until the end of ESD ( from 0 to $120 \mathrm{~min}$; however, if ESD was finished earlier, measurement was terminated; if ESD lasted longer, measurement was terminated at $120 \mathrm{~min}$. that's because under the stable $\mathrm{CO} 2$ insufflation, $\triangle \mathrm{PETCO} 2$ doesn't change so much ). Arterial blood gas $\mathrm{pH}$ was measured in both groups just before ESD, and after ESD subsequently to 3DCT (about 15 minutes later after ESD finished). The visual analogue system (VAS) scores for postoperative symptoms were recorded after the procedure.

\section{Duodenal balloon occlusion method}

We used the balloon for esophageal variceal injection sclerotherapy. We made a circular ring with a nylon thread at the tip of the balloon to create a better grip, grasped this circular ring with a gripping forceps, and inserted it through the overtube into the duodenal bulb. We infused an appropriate amount of air as calculated for previous gastric fluoroscopy $(60-70 \mathrm{~mL}$ on average) to fix the balloon (Figure 1). During the procedure, an overtube was used to allow backflow of $\mathrm{CO}_{2}$ gas from the stomach to the oral cavity for evacuation from the mouth, preventing the gas from flowing into the trachea and lungs. This overtube with no valve could evacuate the backflowing gas from the body.

\section{DCT (intestinal gas volume)}

Reconstructions of 3DCT and measurements of intestinal gas volume were performed and calculated by radiology technician Dr. Masaomi Ohkubo. 3DCTs were 


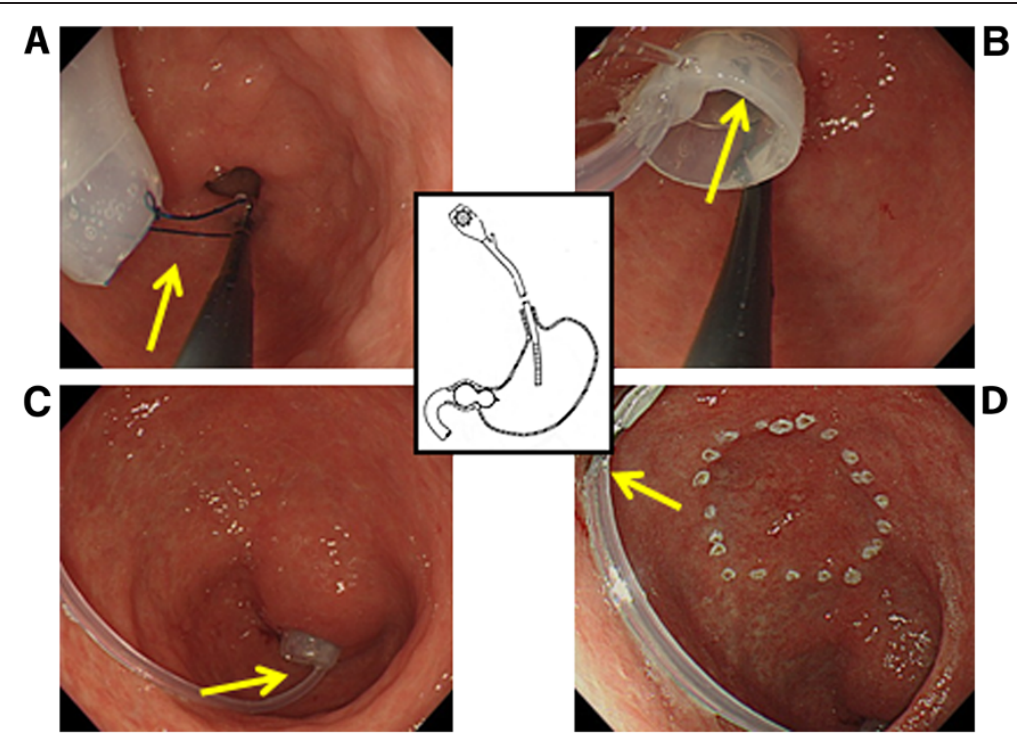

Figure 1 (A) A circular ring was made with a nylon thread at the tip of the balloon to create a better grip. (B) This circular ring was grasped with a gripping forceps and inserted into the duodenal bulb. (C) The balloon was dilated with 60 to $70 \mathrm{~mL}$ of air. (D) The intragastric insufflation tube was clipped onto the gastric wall to prevent the insufflation tube from interfering with the lesion to be removed.

reconstructed from raw $\mathrm{CT}$ images by volume rendering (VR) technique. The cut off level of VR was set at $-400 \mathrm{HU}$. The voltage was $120 \mathrm{kV}$ and the electric current was $200 \mathrm{~mA}$. Raw Slice thickening was $1 \mathrm{~mm}$ and reconstruction was $0.8 \mathrm{~mm}$, and using these parameters, the accuracy of calculated intestinal volumes was $99.5 \%$.

\section{Outcomes}

The primary outcome was the intestinal volume measured by 3DCT before and after ESD using the duodenal balloon occlusion method compared with that of the regular group. The secondary outcome was the intraoperative change in $\mathrm{CO}_{2}$ concentration between the two groups as measured by a capnometer (end-tidal $\mathrm{CO}_{2}$; $\mathrm{PETCO}_{2}$ ) every $10 \mathrm{~min}$ until the end of ESD. Differences in arterial blood gas $\mathrm{pH}$ between the two groups were measured immediately before and after ESD. Patients' abdominal symptoms after ESD as scored using the VAS ranged from 0 (no symptoms) to 10 (severe symptoms).

\section{Statistical analysis and sample size}

The null hypothesis was that the intestinal $\mathrm{CO}_{2}$ gas volumes measured by 3DCT before and after ESD using the duodenal balloon occlusion method would be identical to those of the regular group.

A previous study using air insufflation with or without duodenal balloon occlusion has been reported [22]. We referred to the study and calculated the target number of 64 subjects per group based on $G^{*}$ Power using the effective size of 0.5 . An effective size of 0.8 resulted in a target number of 25 . Based on these numbers, we decided to use a target number of 44 to 45 .

\section{Randomizations and procedures}

This was a single-center, randomized, case control study. Patients were randomly allocated by the sealed envelope method. The randomization was achieved using sealed numbered envelopes, prepared previously by Dr. H. K. The randomization code was not broken until the study was completed. All investigators attended a study meeting before the study and received instructions on performance of the duodenal balloon occlusion method. $\mathrm{PETCO}_{2}$ was recorded every $10 \mathrm{~min}$ from the start of ESD to the end of ESD by nurses who were not notified about this study. CT scans, reconstructions of 3DCT images, and calculations of intestinal $\mathrm{CO}_{2}$ gas were performed respectively by separate radiology technicians who were not notified about this study.

All ESD procedures were performed by one JGEScertified endoscopist (H. M.) with experience of more than 150 cases annually. After all studies were finished, the data were analyzed by Drs. S. F. and H. K. This prospective clinical study was conducted after approval by the institutional ethics committee of Kagawa University Hospital and was enrolled with the University Hospital Medical Information Network (ID: 000003742).

Patients' baseline statistics were analyzed using the unpaired $t$-test, Fisher's exact test, and the Mann-Whitney $\mathrm{U}$-test. Statistical significance was accepted for $\mathrm{P}$ values of $<0.05$. $\mathrm{PETCO}_{2}$ was analyzed every $10 \mathrm{~min}$ by repeated measure ANOVA (Graph Pad Prism 5). 


\section{Results}

\section{Study population}

A total of 44 subjects were enrolled in this study. One subject did not continue treatment because of massive bleeding during ESD. The remaining 43 subjects underwent subsequent endoscopic treatments according to the study protocol. Twenty-one subjects were randomly

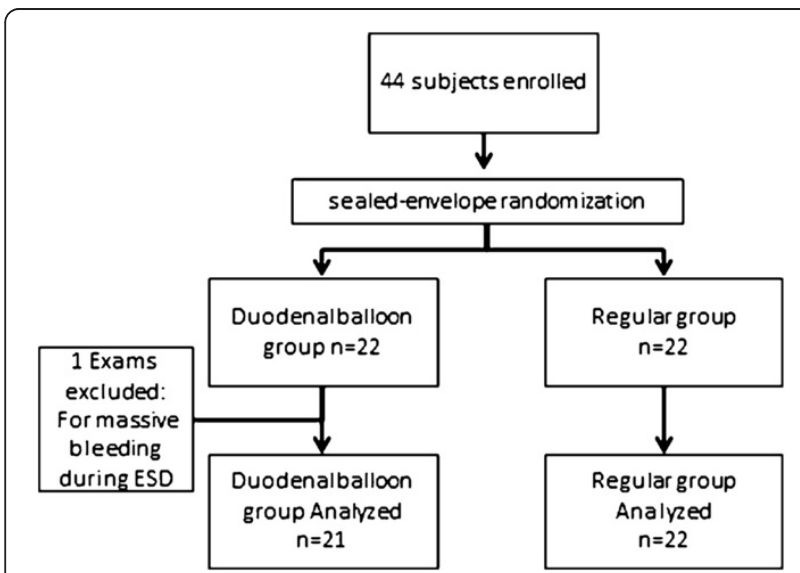

Figure 2 A total of 44 subjects were enrolled. One subject did not continue treatment because of massive bleeding during ESD. The remaining 43 subjects underwent subsequent endoscopic treatments according to the study protocol. Twenty-one subjects were randomly assigned to the duodenal balloon group and 22 to the placebo (regular) group. assigned to the duodenal balloon group and 22 to the placebo (regular) group. The allocation of the patients to the study groups and reasons for exclusion are shown in Figure 2. The baseline characteristics of the two groups were well matched, and no significant differences were found between the 43 patients with respect to age, gender, location of lesion, size of resected lesion, or procedure time (Table 1).

\section{Primary outcome}

The duodenal balloon group showed no significant difference in intestinal volume before $(213.4 \pm 118.8 \mathrm{~mL})$ or after $(256.0 \pm 124.4 \mathrm{~mL})$ ESD. On the other hand, the regular group showed a significant difference before $(214.0 \pm 29.85 \mathrm{~mL})$ and after $(350.9 \pm 33.17 \mathrm{~mL})$ ESD $(P=0.005)$. The amount of increase in intestinal volume ( $\Delta$ volume) before and after ESD was significantly lower in the duodenal balloon group $(25.14 \pm 24.91 \mathrm{~mL})$ than in the regular group $(130.15 \pm 86.52 \mathrm{~mL})(P=0.00027)$ (Figure 3$)$.

\section{Secondary outcomes}

The $\mathrm{PETCO}_{2}$ level from 10 to $120 \mathrm{~min}$ after the start of ESD was significantly lower in the duodenal balloon group $(22.1 \pm 4.74 \mathrm{mmHg})$ than in the regular group $(46.6 \pm 1.69 \mathrm{mmHg})(P=0.0001)$ (Figure 4$)$

In terms of arterial blood gas analysis before and just after ESD, $\mathrm{pH}$ of the duodenal balloon group showed no significant difference $(P=0.423)$, but a significant difference was seen in the regular group $(P=0.037)$. The $\Delta \mathrm{pH}$

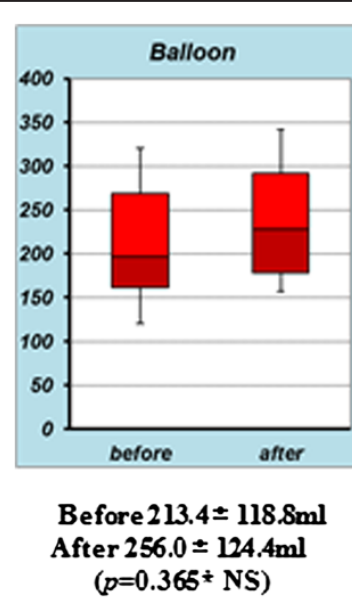

before-and after- ESD Volume

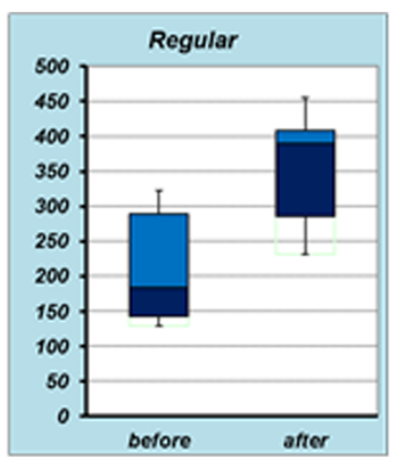

\section{Before $214.0 \pm 29.85 \mathrm{ml}$ After $3509 \pm 33.17 \mathrm{~m}$ $\left(p=0.005^{*}\right)$}

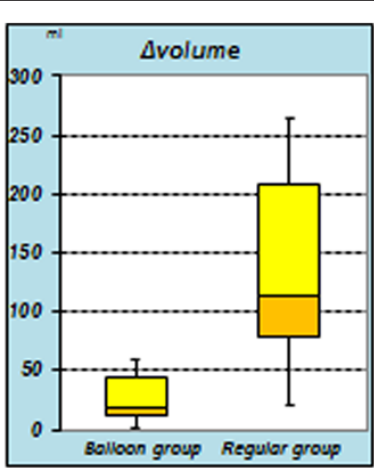

mean $\neq$ SD

$25.14 \div 24.91 \mathrm{mlvs} 130.15 \div 86.52 \mathrm{ml}$

$\left(p=0.00027^{*}\right)$

Avolume

\section{* Mann-Whitney U-test}

Figure 3 The duodenal balloon group showed no significant difference in intestinal volume before (213.4 $\pm 118.8 \mathrm{~mL})$ or after $(\mathbf{2 5 6 . 0} \pm \mathbf{1 2 4 . 4} \mathbf{m L})$ ESD. The regular group showed a significant difference before $(214.0 \pm 29.85 \mathrm{~mL})$ and after $(350.9 \pm 33.17 \mathrm{~mL}) \mathrm{ESD}(P=0.005)$ The $\Delta$ volume before and after ESD was significantly lower in the duodenal balloon group $(25.14 \pm 24.91 \mathrm{~mL})$ than in the regular group $(130.15 \pm 86.52 \mathrm{~mL})(P=0.00027)$. 


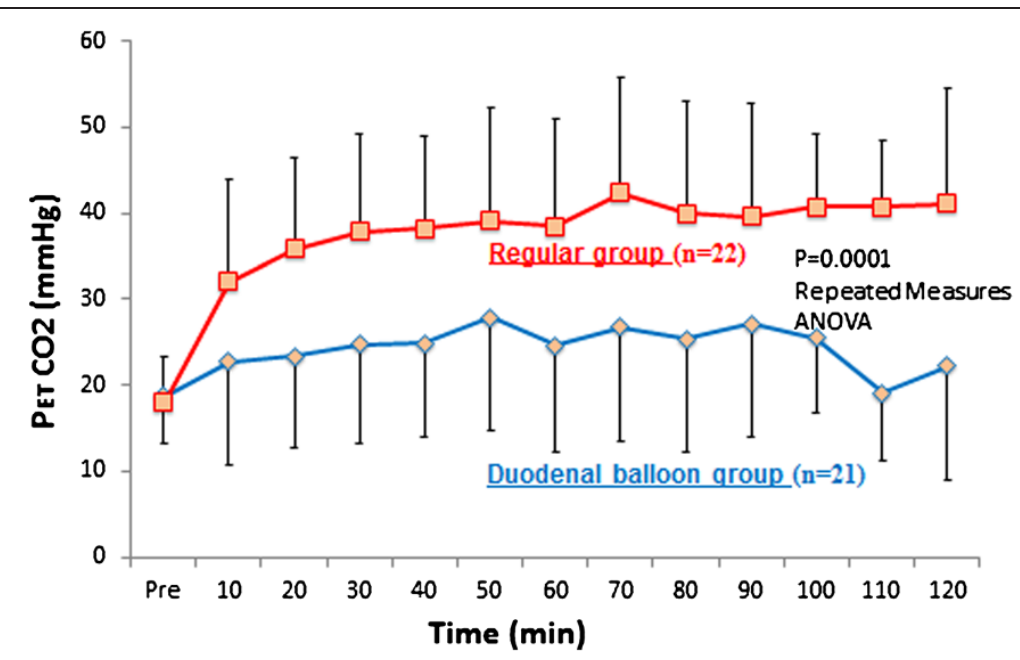

Figure 4 The $\mathrm{PETCO}_{2}$ level from 10 to $120 \mathrm{~min}$ after the start of ESD was significantly lower in the duodenal balloon group $(22.1 \pm 4.74 \mathrm{mmHg})$ than in the regular group $(46.6 \pm 1.69 \mathrm{mmHg})(P=0.0001)$.

between the two groups showed no significant difference $(P=0.549)$ (Figure 5).

As shown in Figures 6 and 7, which depict Case 5 (duodenal group) and Case 36 (regular group), the intestinal $\mathrm{CO}_{2}$ gas volume just before and after ESD was lower in the duodenal balloon group than in the regular group.

The VAS score for the occurrence of nausea due to abdominal distension after ESD ranged from 0 to 1 in the duodenal balloon group and from 3 to 7 in the regular group, revealing a significant difference $(\mathrm{P}=0.031)$ (Figure 8).

\section{Discussion}

The advantage of $\mathrm{CO}_{2}$-insufflated ESD for early colorectal cancer has been previously reported [10]. Complication associated with $\mathrm{CO} 2$ insufflation such as $\mathrm{CO} 2$ narcosis and gas embolism wasn't seen [11]. Several studies has been reported about the influences of $\mathrm{CO}_{2}$ insufflation on the human body during ESD of the upper gastrointestinal (GI) tract, and it is well known that carbon dioxide is absorbed faster in the body than air and also that it is rapidly excreted through respiration without any complications [12]. And it is also reported that insufflation of $\mathrm{CO} 2$ than air during esophageal ESD

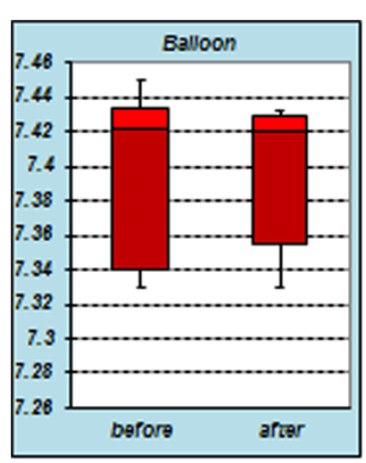

Before 7.420 \pm 0.048

After $7.399 \pm 0.043$ $(p=0.423 * \mathrm{NS})$

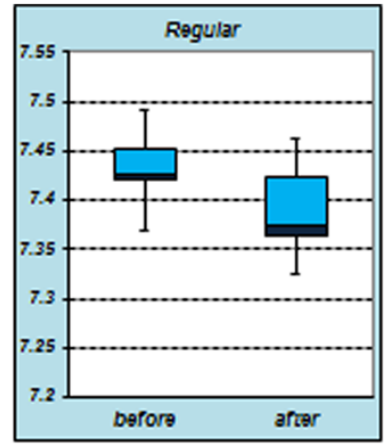

Before 7.426 \pm 0.041 After $7.388 \pm 0.061$ $\left(p=0.037^{\star}\right)$

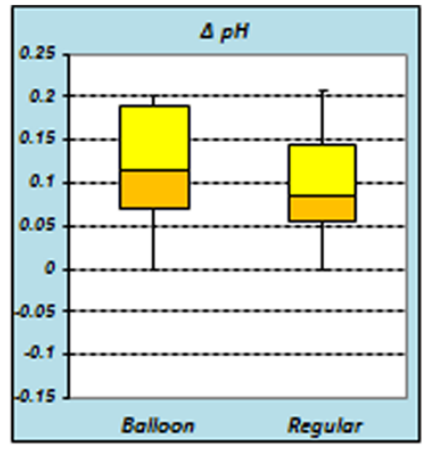

mean \pm SD

$0.0275 \pm 0.0762$ vs $0.0385 \pm 0.0796$ $(p=0.549 * \mathrm{NS})$

\section{before- and after- ESD pH}

$\Delta \mathrm{pH}$

\section{* Mann-Whitney U-test}

Figure 5 The $\mathrm{pH}$ of the duodenal balloon group showed no significant difference $(P=0.423)$, but a significant difference was seen in the regular group $(P=0.037)$. The $\Delta \mathrm{pH}$ showed no significant difference between the two groups $(P=0.549)$. 


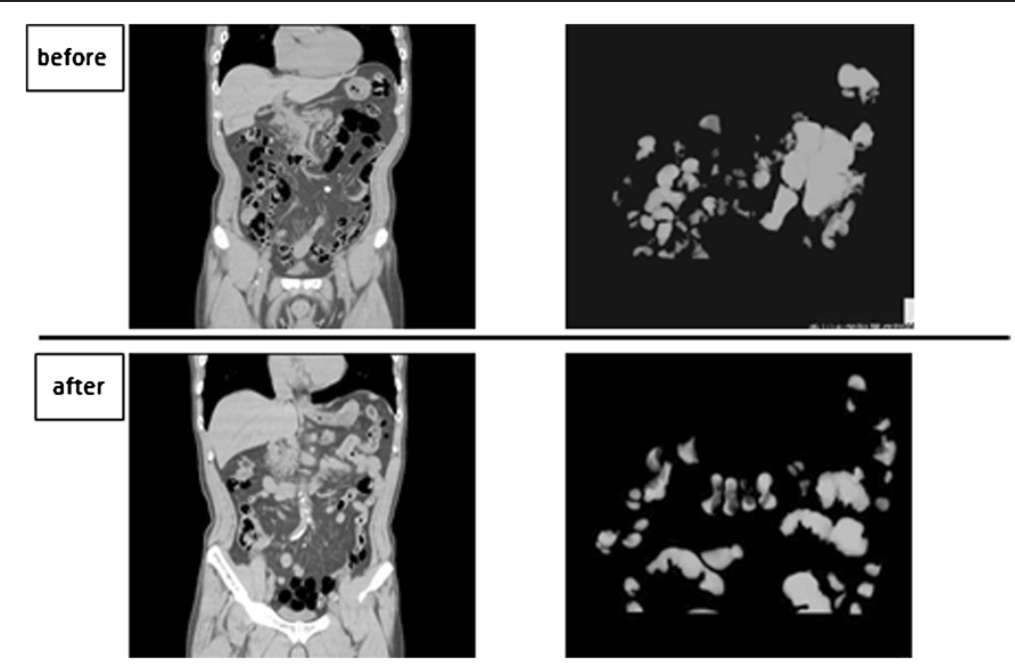

Figures 6 Duodenal balloon group: CT coronal image \& 3D image. Two cases are depicted: Case 5 (duodenal balloon group) and Case 36 (regular group). 3DCT showed that the intestinal CO2 gas volume was relatively lower in the duodenal balloon group than in the regular group.

significantly reduced postprocedural mediastinal emphysema [13]. In $\mathrm{CO}_{2}$-insufflated ESD for early colorectal cancer, $\mathrm{CO}_{2}$ gas is insufflated retrogradely, Bauhin's valve functions as a backflow-prevention system, and the $\mathrm{CO}_{2}$ is absorbed only through the colonic mucosa.

In esophageal or gastric $\mathrm{CO}_{2}$-insufflated $\mathrm{ESD}, \mathrm{CO}_{2}$ gas insufflated into the upper GI tract is widely distributed to and absorbed rapidly through not only the esophagus and stomach, but also other parts of the GI tract, such as the intestine. This suggests two potential effects of esophageal or gastric $\mathrm{CO}_{2}$-insufflated ESD on the human body.
First, massive insufflated $\mathrm{CO}_{2}$ gas into the stomach, duodenum, and intestine during or after ESD may worsen patient symptoms such as nausea and abdominal distension to some extent. Its volume effects may also influence patients' respiratory functions. Our study reveals that a greater amount of $\mathrm{CO}_{2}$ gas was insufflated and remained after ESD without the duodenal balloon, and it affected patients' symptoms (such as nausea) to some extent. We believe that the total insufflated $\mathrm{CO}_{2}$ gas volume should be controlled as little as possible whether or not it may have an unfavorable effect on the human body. A small $\mathrm{CO}_{2}$ gas volume is economical in terms of
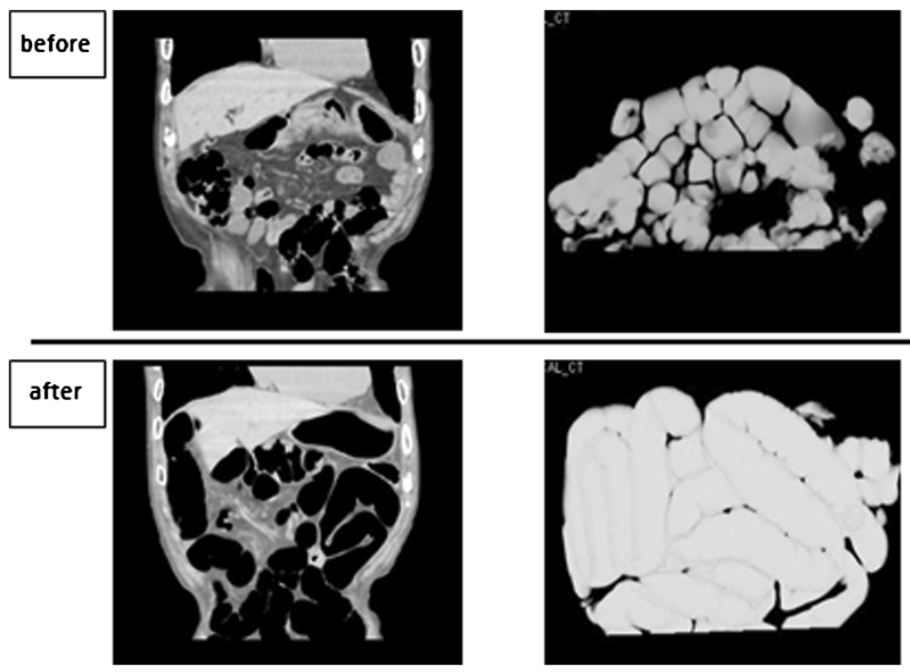

Figure 7 Regular group: CT coronal image \& 3D image. Two cases are depicted: Case 5 (duodenal balloon group) and Case 36 (regular group). 3DCT showed that the intestinal CO2 gas volume was relatively lower in the duodenal balloon group than in the regular group. 


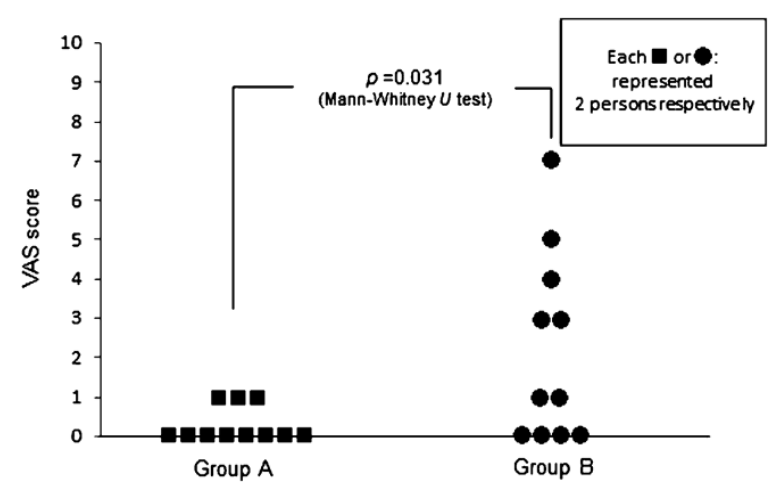

Figure 8 The VAS scores ( 0 to 10 ) for the occurrence of nausea due to abdominal distension after ESD ranged from 0 to 1 in the duodenal balloon group and from 3 to 7 in the regular group, showing a significant difference between the two groups $(P=0.031)$.

medical expense because it can reduce the cost of purchasing $\mathrm{CO}_{2}$.

Second, massive insufflated $\mathrm{CO}_{2}$ gas may affect patients' blood gas analysis. In this study, changes in the $\mathrm{CO}_{2}$ level during ESD were examined by $\mathrm{PETCO}_{2}$ as measured by a capnometer that indirectly suggested the arterial blood $\mathrm{CO}_{2}$ concentration [23]. In the duodenal balloon group, the mean $\mathrm{PETCO}_{2}$ measured during ESD $(22.1 \pm 4.74 \mathrm{mmHg})$ was significantly lower than that of the regular group $(46.6 \pm 1.69 \mathrm{mmHg})(P=0.0001)$. We did not observe significant differences in $\Delta \mathrm{pH}$ between the two groups, but just after ESD in the regular group, there was a significant difference in $\mathrm{pH}(P=0.037)$. This also implies that the arterial blood $\mathrm{CO}_{2}$ concentration levels in the regular group during ESD were higher than those of the balloon group. We sometimes perform ESD under general anesthesia if it will take longer because of the presence of a complicated lesion. When we performed ESD for a prolonged period under general anesthesia, some patients who underwent ESD with $\mathrm{CO}_{2}$ insufflation without the balloon showed dangerously high $\mathrm{CO}_{2}$ concentration levels (around $60 \mathrm{mmHg}$ ) during ESD. We were also advised that maintaining a high $\mathrm{PETCO}_{2}$ level during ESD should be avoided to prevent the risk of respiratory depression in patients with chronic obstructive respiratory disease (COPD). Therefore, in such COPD cases, the duodenal balloon method is preferable because it can maintain $\mathrm{PETCO}_{2}$ at low levels during ESD.

Furthermore, during procedures such as laparoscopic endoscopic cooperative surgery or hybrid natural orifice transluminal endoscopic surgery [24], a clear operational view without intestinal distension is helpful in obtaining a good laparoscopic field of view in our hospital.

\section{Conclusions}

$\mathrm{CO}_{2}$-insufflated ESD for early esophageal or gastric cancer was proven safe for early colorectal cancer. However, the use of the duodenal balloon occlusion method in ESD for early esophageal or gastric cancer may reduce unnecessary insufflation of $\mathrm{CO}_{2}$ and prevent $\mathrm{CO}_{2}$ gas from flowing into the intestine, which can maintain a lower $\mathrm{CO}_{2}$ level in patients with COPD.

Limitations of this study were its single-center nature and small sample size.

\section{Competing interests}

The authors declare that they have no competing interests.

\section{Acknowledgements}

This study was supported by Kagawa University Hospital in 2010. Written consent for publication was obtained from the patients or their relatives.

\section{Author details}

${ }^{1}$ Department of Gastroenterology and Neurology, 1750-1 Ikenobe, Miki, Kita, Kagawa 761-0793, Japan. ${ }^{2}$ Department of Gastroenterological Surgery, 1750-1 Ikenobe, Miki, Kita, Kagawa 761-0793, Japan. ${ }^{3}$ Department of Radiology, 17501 Ikenobe, Miki, Kita, Kagawa 761-0793, Japan. ${ }^{4}$ Department of Pharmacology, Kagawa Medical University School of Medicine, 1750-1 Ikenobe, Miki, Kita, Kagawa 761-0793, Japan.

\section{Authors' contributions}

Analysis and interpretation of the data was performed by HK, SF, NN, KR, MO and $\mathrm{KI}$. Critical revision of the article for important intellectual content was performed by YS and TM. Final approval of the article was performed by TM. All authors read and approved the final manuscript.

Received: 18 October 2011 Accepted: 24 April 2012

Published: 24 April 2012

\section{References}

1. Oyama T, Tomori A, Hotta K, et al: Endoscopic submucosal dissection of early esophageal cancer. Clin Gastroenterol Hepatol 2005, 3:67-70.

2. Fujishiro M, Yahagi N, Kakushima N, et al: Endoscopic submucosal dissection of esophageal squamous cell neoplasm. Clin gastroenterol Hepato 2006, 14:688-694.

3. Ono H, Kondo $H$, Gotoda $T$, et al: Endoscopic submucosal dissection for treatment of early gastric cancer. Gut 2001, 48:225-229.

4. Yamamoto $H$, Kawata $H$, Sunada $K$, et al: Successful en bloc resection of large superficial tumor in the stomach and colon using sodium hyaluronate and small-caliber-tip transparent hood. Endoscopy 2003, 35:690-694.

5. Gotoda T: A large endoscopic resection by endoscopic submucosal dissection procedure for early gastric cancer. Clin Gastroenterol Hepatol 2005, 3(7 Suppl 1):S71-S73.

6. Takahashi T, Ando T, Kabeshima Y, et al: Borderline cases between benignancy and malignancy of the duodenum diagnosed successfully by endoscopic submucosal dissection. Scand J Gastroenterol 2009, 44:1377-83

7. Oda I, Gotoda T, Hamanaka H, et al: Endoscopic submucosal dissection of early gastric cancer: technical feasibility, operation time, and complications from a large consecutive series. Dig Endosc 2005, 17:54-58.

8. Takizawa K, Oda I, Gotoda T, et al: Routine coagulation of visible vessels may prevent delayed bleeding after endoscopic submucosal dissection: an analysis of risk factors. Endoscopy 2008, 40:179-183.

9. Bretthauer M, Lynge $A B$, Thiis-Evensen $E$, et al: Carbon dioxide insufflation in colonoscopy: safety and effectiveness in sedated patients. Endosc 2005, 37:706-709.

10. Saito $Y$, Uraoka T, Matsuda T, et al: A pilot study to assess safety and efficacy of carbon dioxide insufflation during colorectal endoscopic submucosal dissection under conscious sedation. Gastrointest Endosc 2007, 65:537-542. 
11. Kikuchi T, Fu Kl, Saito Y, et al: Transcutaneous monitoring of partial pressure of carbon dioxide during endoscopic submucosal dissection of early colorectal neoplasia with carbon dioxide insufflation: a prospective study. Surg Endosc 2010, 24:2231-2235.

12. Nonaka S, Saito $Y$, Takizawa $H$, et al: Safety of carbon dioxide insufflation for upper gastrointestinal tract endoscopic treatment of patients under deep sedation. Surg Endosc 2010, 24:1638-1645.

13. YMaedaDHirasawaNFujita2012et alA pilot study to assess mediastinal emphysema after esophageal endoscopic submucosal dissection with carbon dioxide insufflationEndoscopy[Epub ahead of print]Maeda $Y$, Hirasawa D, Fujita N: et al. Endoscopy: A pilot study to assess mediastinal emphysema after esophageal endoscopic submucosal dissection with carbon dioxide insufflation; 2012 [Epub ahead of print].

14. Hussein $\mathrm{AM}$, Bartram $\mathrm{Cl}$, Williams $\mathrm{CB}$, et al: Carbon dioxide insufflation for more comfortable colonoscopy. Gastrointest Endosc 1984, 30:68-70.

15. Stevenson GW, Wilson JA, Wilkinson J, et al: Pain following colonoscopy: elimination with carbon dioxide. Gastrointest Endosc 1992, 38:564-567.

16. Church J, Delaney C: Randomized controlled trial of carbon dioxide insufflation during colonoscopy. Dis Colon Rectum 2003, 46:322-326.

17. Bretthauer M, Thiis-Evensen E, Huppertz-Hauss G, et al: A randomized trial to assess the safety and efficacy of carbon dioxide versus air insufflation in colonoscopy. Gut 2002, 50:604-607.

18. Minami S, Gotoda T, Ono H, et al: Complete endoscopic closure of gastric perforation induced by endoscopic resection of early gastric cancer using endoclips can prevent surgery. Gastrointest Endosc 2006, 63:596-601.

19. Fujishiro M, Yahagi N, Kakushima N, et al: Successful nonsurgical management of perforation complicating endoscopic submucosal dissection of gastrointestinal epithelial neoplasm. Endoscopy 2006 , 38:1001-1006.

20. Hayakawa M, Gando S, Kameue T, et al: Abdominal compartment syndrome and intrahepatic portal venous gas: a possible complication of endoscopy. Intensive Care Med 2002, 28:1680-1681.

21. Pepprielli JE, Bacon DR: Acute abdominal compartment syndrome with pulselese electrical activity during colonoscopy with conscious sedation. J Clin Anesth 2000, 12:216-219.

22. Mori H, Kobara H, Masaki T, et al: A new technique for safer endoscopic submucosal dissection using the duodenal balloon occlusion method. J Gastroent and Hepatology 2012, 27:81-85.

23. Corbo J, Bijur P, Lahn M, et al: Concordance between capnography and arterial blood gas measurements of carbon dioxide in acute asthma. Ann Emerg Med 2005, 46(4):323-327.

24. Ludwig K, Wilhelm L, Scharlau U, et al: Laparoscopic-endoscopic rendezvous resection of gastric tumors. Surg Endosc 2002, 16:1561-1565.

doi:10.1186/1471-230X-12-37

Cite this article as: Mori et al: Effectiveness of $\mathrm{CO}_{2}$-insufflated endoscopic submucosal dissection with the duodenal balloon occlusion method for early esophageal or gastric cancer: a randomized case control prospective study. BMC Gastroenterology 2012 $12: 37$.

\section{Submit your next manuscript to BioMed Central and take full advantage of:}

- Convenient online submission

- Thorough peer review

- No space constraints or color figure charges

- Immediate publication on acceptance

- Inclusion in PubMed, CAS, Scopus and Google Scholar

- Research which is freely available for redistribution 